\title{
Students' Perspectives on CLIL Programme Development: A Quantitative Analysis
}

\author{
Gina Louise OxBrow \\ University of Las Palmas de Gran Canaria
}

Received: 23 May 2017 / Accepted: 2 October 2017

ISSN: $1697-7467$

\begin{abstract}
This article presents the outcomes of a large-scale programme evaluation into students' perspectives on CLIL programme development. To this end, questionnaires were administered to 221 students in the Canary Islands (Spain) in order to carry out an in-depth analysis of where we stand in the process of implementing CLIL. After framing the topic against the backdrop of prior investigations and substantiating the need for a study of this nature, the article expounds on its research design and outlines its main findings in relation to the ten main fields of interest which have been canvassed: L2 use in class, L2 development: discursive functions, competence development, methodology and types of groupings, materials and resources, coordination and organization, evaluation, motivation and workload, and overall appraisal of bilingual programs. A detailed diagnosis of where we currently stand in this process of implementation of CLIL pedagogy is provided and within-cohort comparisons are carried out in terms of a series of identification variables.
\end{abstract}

Keywords: CLIL, pedagogy, survey, learner perspectives, learner variables

Las perspectivas del alumnado sobre el desarrollo de los programas AICLE: Un análisis cuantitativo

RESUMEN: Este artículo presenta los resultados de un proyecto de investigación diseñado para evaluar las perspectivas de estudiantes sobre el desarrollo de programas AICLE. Para ello, se han administrado cuestionarios a 221 sujetos en las Islas Canarias (España) para llevar a cabo un análisis detallado sobre la efectividad actual del proceso de implementación de los proyectos AICLE. Después de un breve repaso de las recientes investigaciones pertinentes que apoyará la necesidad de un estudio de esta naturaleza, se describe el diseño de este proyecto de investigación y se detallan los principales hallazgos en relación con las diez áreas de interés que han sido exploradas: las funciones discursivas, de desarrollo de competencias, la metodología y tipos de agrupamiento utilizados en clase, los materiales y recursos empleados, la coordinación y organización de los profesores, la evaluación, la motivación y la carga de trabajo, junto con una evaluación general de los programas bilingües. Se proporciona un diagnóstico detallado sobre el actual funcionamiento del proceso de implementación de una pedagogía AICLE y se lleva a cabo una comparación intra-grupal en función de una serie de variables de identificación.

Palabras claves: CLIL, pedagogía, cuestionarios, perspectivas del alumnado, variables de identificación

\section{INTRODUCTION}

The growing implementation of bilingual approaches and CLIL pedagogy in interdisciplinary educational spheres is undoubtedly an escalating phenomenon, especially in the current European educational context (Pérez-Vidal, 2013). It is arguably the most innovative 
didactic reform of the last couple of decades in response to the emergent twenty-first century need for multilingual citizens who need to be competent in more than one language. It could also be viewed as a valiant attempt to respond to the parallel need to tackle foreign language (FL) learning deficits ${ }^{1}$ that are spreading beyond educational, professional or research contexts and encompassing the need for greater social integration with ever-increasing migratory movements (Lasagabaster \& Sierra, 2009: 4). With respect to foreign language learning and teaching, and on reviewing the last two decades from the initial inception of CLIL programmes in formal education at Primary and later Secondary levels, we are witnessing how the dual-focused approach of Content and Language Integrated Learning (CLIL) has been heralded as the lynchpin for change and success in language learning (Doiz et al. 2014; Pérez Cañado, 2014). Coyle (2013: 244) has also recently observed that CLIL seems to be evolving into a "catalyst for conceptualising and re-conceptualising how languages can be used as both the medium and the object of learning in very different global contexts".

From a national vantage point, Spain is rapidly becoming one of the European leaders in CLIL practice and research (Coyle et al., 2010: viii), and has produced a plethora of research studies validating the success of CLIL programmes (Cenoz, et al., 2013; Lasagabaster, 2011; Lasagabaster and Sierra, 2009; Peña Díaz and Porto Requejo, 2008; Pérez Cañado, 2014; Pérez Vidal, 2013). The current article will present some of the relevant outcomes of a recent large-scale evaluation that has been undertaken under the auspices of a longitudinal ministry-funded research project into the effects of CLIL on both English and Spanish language competence, as well as on content knowledge of those subjects taught through the FL, with both Primary and Secondary students in 12 different provinces of Spain ${ }^{2}$. Consequently, it will provide a survey of one of the key stakeholder perspectives extracted from the data collected so far in the Canary Islands: the viewpoint of the students involved in this type of dual-focused teaching and learning programme. As such, we have worked with 221 students from both $6^{\text {th }}$ grade Primary and $4^{\text {th }}$ grade Secondary levels who are enrolled in CLIL programmes in a total of eight schools: four Primary and four Secondary centres.

After framing the research topic of learner perspectives on bilingual education within the relevant body of published prior investigation, which will provide a relevant background in order to substantiate the need for the current study, the design of this longitudinal investigation will be briefly described. We shall outline the research objectives, and then describe our sample, the variables focused on, the quantitative research instrument employed, our questionnaire validation and the statistical methodology employed in the present analysis. Subsequently, the main findings will be expounded in relation to the fields of interest which have been surveyed: L2 use in class, L2 development, competence development, methodology and types of groupings, materials and resources, teacher coordination and organization, evaluation, motivation and workload, and finally an overall appraisal of bilingual programmes in the Canary Islands. The data gathered will be subsumed and commented on within the seven thematic blocks which comprise the questionnaire administered, and will be analysed

\footnotetext{
${ }^{1}$ The urgency for improvement in foreign language learning in Europe has led to a substantial increase in political, administrative and economic investment. See Pérez-Cañado (2014) for how this has translated into teacher training needs.

${ }^{2}$ This MON-CLIL research project was supported by the Spanish Ministry of Economy and Competitiveness, under Grant FFI2012-32221, and by the Junta de Andalucía, under Grant P12-HUM-23480.
} 
firstly in global terms, before moving onto the specific results provided in terms of the identification variables we have selected for our sample. Hence, using selected data gathered within the MON-CLIL project addressing the implementation of bilingual programmes in our monolingual community, we shall explore the perceived effectiveness of learning English through the medium of other subjects from the perspectives of the students involved at the front line in this type of dual-focused programme in our local context, and explore the interplay of a number of possible identification variables.

\section{TheORETICAL BACKDROP}

To date, there has been noticeably limited prior research addressing the nature of student perspectives with regard to their participation in CLIL programmes across Europe and in Spain, since most published studies have focused either on the effects of CLIL on FL learning processes, on the development of the L1, or on subject matter competence rather than on other variables such as those which will be addressed in the current section. As already highlighted above, these include learners' perceived development of their L2 competence, as well as their view of L2 use in class, teacher methodology, coordination and resources, and the effect on an increased workload on their motivation. A valuable exception is the study carried out in the Basque country by Cenoz (2001, cited in Lasagabaster \& Sierra, 2009) analysing the attitudes towards English of three different groups of students: (i) fourth year of Primary Education (9-10 year olds); (ii) second-year Secondary Education students (13-14 year olds) and (ii) first-year Baccalaureate students (16-17 year olds). The results obtained revealed that significantly more positive attitudes were to be found in the youngest age group and these gradually diminished with the older groups. This finding was also replicated in a similar study carried out in the Basque country by Lasagabaster and Sierra (2009). The variable corresponding to the number of years that students have been learning the FL will also be included in the research reported in the current study.

Along with the notable paucity of published studies on a national level, even more worrying is the almost total lack of empirical research addressing the effect of the continuing implementation of bilingual programmes in growing numbers of educational institutions in the Canary Islands, which has now become a fundamental need due to the successful expansion of CLIL pedagogy in this province. A recent report, commissioned by the Canarian Government and conducted by Frigols and Marsh (2014), focuses on methodological issues as well as the implication of students, teachers and parents. This publication has highlighted the growing success of CLIL programmes; in the words of Frigols, "The Canaries has one of the best CLIL programmes in English in Spain"3. Although the report highlights the solid backing of CLIL programmes in the Canary Islands on the part of all three of these stakeholder groups along with that of the local government, other aspects such as the high levels of cooperation between both teachers and teachers and the school leadership team also stand out, as well as the provision of opportunities for the professional interdisciplinary

\footnotetext{
${ }^{3}$ From the news section on the Canarian Government website: http://www.gobcan.es/noticias/historico/Educacion_Universidades_Sostenibilidad/55471/maria-jesus-frigols-canarias-cuenta-mejores-programas-clil-inglesespana.
} 
development of the teachers involved, who were also described as highly motivated and well versed in the use of ICT tools in classes. This will be an area for further research here from the perspective of the learners. As for the students, again they were found to be highly motivated, and attracted by content subjects given in English. They also appeared to be aware of the positive repercussions of a dual-focused CLIL approach in their academic formation and gave the impression of developing greater autonomy, while their written and oral expression in the target language improved, too. Once again, these variables will be focused on here.

Thus, it might seem that a focus on learner perspectives in educational research could be a revealing source of data, and this is where the strength of the research reported here lies. Recently, and in a context which is not particularly well-known for its success in FL learning and teaching, Coyle (2013) focused on the value of exploring learner perspectives of CLIL programmes in the UK and argued that we need to survey the opinions of students with regard to the quality and nature of their experiences in order to enable their learning to become more successful. In her words:

Arguably it is the process of data gathering and reflection which will influence classroom practice in any context where strategies for 'successful learning' emerge from what learners say and do, but at the same time listening to learners provides a frame of reference about how situated professional practice needs to change if successful content and language integrated learning is to be sustained across very different contexts. (Coyle, 2013: 266)

Cenoz et al. (2013) and Dalton-Puffer et al. (2014) have also recognised the pressing need for research into the effectiveness of CLIL programmes that attends to diversity and singles out individual learner variables which might have a bearing on successful learning as bilingual programmes continue to expand to all types of students. Previous research undertaken in CLIL has primarily compared language learning outcomes with CLIL or non-CLIL groups without either guaranteeing their homogeneity of factoring in possible moderating variables. Other concerns which require further investigative attention and whose deficits have been well-documented in the recent literature are the design and provision of appropriate student-centred methodologies and materials (Pérez Cañado, 2014: 4); both of these variables will be addressed in the study presented here from the student perspective rather than the previous almost exclusive focus on teachers in this regard.

There seems to be little doubt that both teachers and students are highly motivated as they face the CLIL challenge and, as Pérez-Vidal (2013: 76) has reminded us, the positive regard of these key stakeholders is fundamental in CLIL since they probably see that "[CLIL] fulfils some of the demands of their mindsets, such as new technologies, access to mobility, and global communication". Motivation is one of the aspects which will be focused on in the data collated and presented in the present analysis, but we will also factor in other possible variables in order to highlight any significant differences within our target cohort, as well as explore other areas relevant to learner perspectives such as their perceived FL development, their teachers' aptitude, along with the resources and materials used in their classes, and also the teaching methodology employed. In summary, the current article hopes to begin to bridge the gap between the paucity of empirical research from this autonomous 
community and the burgeoning research being produced in other contexts in Spain such as Andalusia and the Basque country.

Having conducted this brief literature review, we can ascertain that there seems to be an imperative need for further empirical research into the perspectives of learners towards their participation in CLIL programmes in Spain, as well as a certain urgency for a greater focus on the Canary Islands, as it is evidently the Spanish monolingual community where the dearth of published studies is most notable. This is where the current article intends to make a contribution, as it seems that a focus on learners' experience of CLIL programmes is clearly warranted, and not merely as a comparison with their non-CLIL counterparts. According to the report published by Frigols and Marsh (2014), CLIL programmes involving the inclusion of at least one content subject given in English were first integrated in the Canary Islands in 2004-2005 in nine Primary Education centres, increasing to 71 Primary and Secondary schools, 1,200 teachers and 19,700 students by 2014. A notable increase in student motivation is evident (in the same way as the research reported by Pérez Vidal, 2013), as well as the development of greater learner autonomy due to the improvement in written expression and oral skills, the greater appeal of subjects given in English, and a higher incidence of group work. Students also seem to be highly aware of the positive repercussions of their participation in the bilingual programme in their academic formation. The programmes have also been positively received by parents, also key stakeholders for the continuation of bilingual programmes, as they consider them to be fundamental for education. The current study will hopefully echo this optimistic vision.

Yet, despite this promising report, and although CLIL programmes have been running in the Canary islands for over ten years, it is definitely time for more stock-taking and this is where the large-scale project reported on here is fully justified as a means to reinforce the necessary symbiotic relationship between academic research and classroom practice. A further justification is the inclusion of an analysis of possible identification factors in the key areas mentioned above, as well as the triangulation and validated research instruments worked with in the present large-scale longitudinal project. To this end, it has administered questionnaires to 221 students in the Canary Islands, Spain in order to carry out an in-depth analysis of where we stand in the process of implementing CLIL ${ }^{4}$.

\section{ObJectives}

It should now be apparent that the main objective of the current article is to focus on learner perspectives of CLIL programmes and the identification of a number of variables from data collated from the large-scale investigation within which the present study has been included, but we can also offer two meta-concerns we shall highlight, which are defined below in terms of student perceptions and a within-cohort comparison.

\footnotetext{
${ }^{4}$ Semi-structured interviews were also conducted within the same cohort of subjects, but these results will be triangulated with the current quantitative data obtained from the questionnaires in a future publication.
} 


\section{Meta-concern 1 (student perceptions)}

To determine the perceptions of students enrolled in bilingual programmes in both Primary and Secondary educational spheres in Gran Canaria according to seven thematic blocks: (i) students' use, competence and development of English in class; (ii) methodology; (iii) materials and resources; (iv) evaluation; (v) teacher's use, competence and development of English in class; (vi) mobility; and (vii) improvement and motivation towards learning English. These blocks correspond to those contained within the questionnaire specifically designed for the government- funded MON-CLIL research project within which the present study is located.

Meta-concern 2 (within-cohort comparison)

To determine whether there are statistically significant differences in terms oflearner perceptions within the cohort of students according to the variables of (i) gender; (ii) level ( $6^{\text {th }}$ grade Primary or $4^{\text {th }}$ grade Secondary; (iii) context (rural or urban); (iv) number of years learning English; and (v) number of subjects received in English. Once again, these variables are those included within the MON-CLIL project.

\section{Research DESIGN}

After framing the topic against the backdrop of prior investigations, and in this way substantiating the need for a study of this nature along with our corresponding research objectives, we shall now turn our attention to our research design and subsequently outline the main findings we have obtained in relation to the main fields of interest which have been canvassed in this project: these are (i) L2 use in class, (ii) L2 development: discursive functions, (iii) competence development, (iv) methodology and types of groupings, (v) materials and resources, (vi) coordination and organization, (vii) evaluation, (viii) motivation and workload, and (ix) an overall appraisal of bilingual programmes. Investigator triangulation has been provided, as different researchers and statisticians have analysed the elicited data in the form of closed-response items from the questionnaires ${ }^{5}$. The present investigation will primarily use quantitative data culled from Phase 2 of the investigation as an instance of survey research using questionnaires. Location triangulation as also been contemplated since the data has been gathered from multiple sites including both Primary and Secondary schools.

\subsection{Sample}

The sample included in the current investigative project has focused on a fairly ample cohort of 221 students from both Primary and Secondary levels ${ }^{6}$ participating in bilingual

\footnotetext{
${ }^{5} \mathrm{~A}$ copy of the questionnaire used can be found online at the following online link: http://revistas.cardenalcisneros.es/index.php/PULSO/article/view/217.

${ }^{6}$ In Spain, Primary Education, students' ages usually range from 6 to 12 years old, with Compulsory Secondary Education comprising students between 12 and 16 years old.
} 
programmes in Gran Canaria, although mainly from Primary levels, with $75 \%$ of the respondents from this group. The seven identification variables which permit a more detailed picture of our participants and are related to gender, educational level or age (Primary or Secondary), nationality, type of centre (public or private), context (rural or urban), years of study of English and the number of subjects received in English. Of the 221 respondents, gender is roughly equally represented with $48.2 \%$ males and $51.8 \%$ females and they are mostly Spanish (87.4\%), with 6.9\% Latin American, 3.9\% other Europeans and $1.9 \%$ from other nationalities.

As regards the type of centre surveyed, most of them are public schools $(91.4 \%)$, with only $8.6 \%$ private schools included in this study. Of these, the majority are urban $(83.3 \%)$, with $16.7 \%$ corresponding to rural contexts. The number of years of learning English was also fairly equally represented by our cohort, since $53.5 \%$ of the subjects had studied English for more than four years and $46.55 \%$ had been learning the target language for fewer than fouryears. In relation to the number of subjects taken in English within our group of participants, over half of them received tuition in fewer than or equal to three subjects $(60.5 \%)$, but a respectable number $(39.5 \%)$ had more than three subjects in English. The subjects included correspond to Science (76,2\%), Social Science (62.3\%), Mathematics (40\%), Music (38.1\%), Art (30.2\%), Physical Education (20.5\%), and 21.4\% to others.

\subsection{Variables}

In terms of the variables focused on, the $M O N-C L I L$ study ${ }^{7}$ reports on the impact of CLIL on eight different cognitive, contextual, and affective variables: context (rural-urban), type of school (public, private, charter), educational level (Primary, Secondary, Baccalaureate), motivation, verbal intelligence, extramural exposure to English, and socioeconomic status (cf. the other articles in this volume). In the case of the present analysis, we have access to a series of possible identification variables from the initial page of questionnaire related to the individual characteristics of the polled respondents which asks for demographic or background information: gender, nationality, type of school (public or private), setting (urban or rural), level (Primary or Secondary), number of years learning English and number of subjects received in English.

\subsection{Instruments}

As we have previously clarified, the survey tool which this study has used is group-administered questionnaires, both designed and validated in Spanish. In order to obtain objective and uniform response, here are a total of 48 closed response items which have been organised in seven thematic blocks using a Likert Scale of 1-4 in order to avoid the central tendency error of five-point scales. The initial version of the questionnaire was carefully validated

\footnotetext{
${ }^{7}$ This design and variables focused on within this research project has been amply described within the scope of the current monograph and thus need no further explanation here. This also applies to the research paradigm employed.
} 
(Pérez Cañado, 2016a), and once the data was collected, the Cronbach alpha value was calculated for each thematic block in order to guarantee internal reliability. Content validity was also guaranteed since curricular aspects defined in official documents were included to reflect consistency with educational requirements.

\subsection{Data analysis: Statistical methodology}

As regards the data analysis and statistical methodology employed, the data obtained on the questionnaires has undergone statistic treatment using the SPSS program in its 21.0 version. Central tendency (mean, median and mode) and dispersion measures (range, lowhigh, and standard deviation) have also been calculated for meta-concern 1. A detailed diagnosis of where we currently stand in this process of implementation of CLIL pedagogy is provided and within-cohort comparisons are carried out in terms of a series of identification variables. Analysis of variance (ANOVA) and the $t$ test have also been employed in the case of Meta-concern 2 in order to unearth the existence of statistically significant differences within the cohort in terms of the identification variables given above.

\section{Results AND discussion}

The following section presents the insights obtained from the quantitative data gathered from the questionnaires distributed to the 221 subjects surveyed who were participating in bilingual programmes at schools on the island of Gran Canaria enrolled in two contrasting levels, $6^{\text {th }}$ grade Primary and $4^{\text {th }}$ grade Secondary levels, according to the profile described previously. The results will be commented on within the seven thematic blocks which the questionnaire was designed to canvass and appear to reveal encouraging insights in relation to these students' perceptions of the success of the implementation of CLIL pedagogy in their teaching and learning contexts.

\subsection{Global results}

In the first place, we shall report on the data obtained from the administration of the questionnaire from a global viewpoint, for which descriptive statistics have been used to report on the results obtained for Meta-concern 1: to determine the perceptions of students enrolled in bilingual programmes in both Primary and Secondary educational settings in Gran Canaria according to seven thematic blocks described in Section 4. 


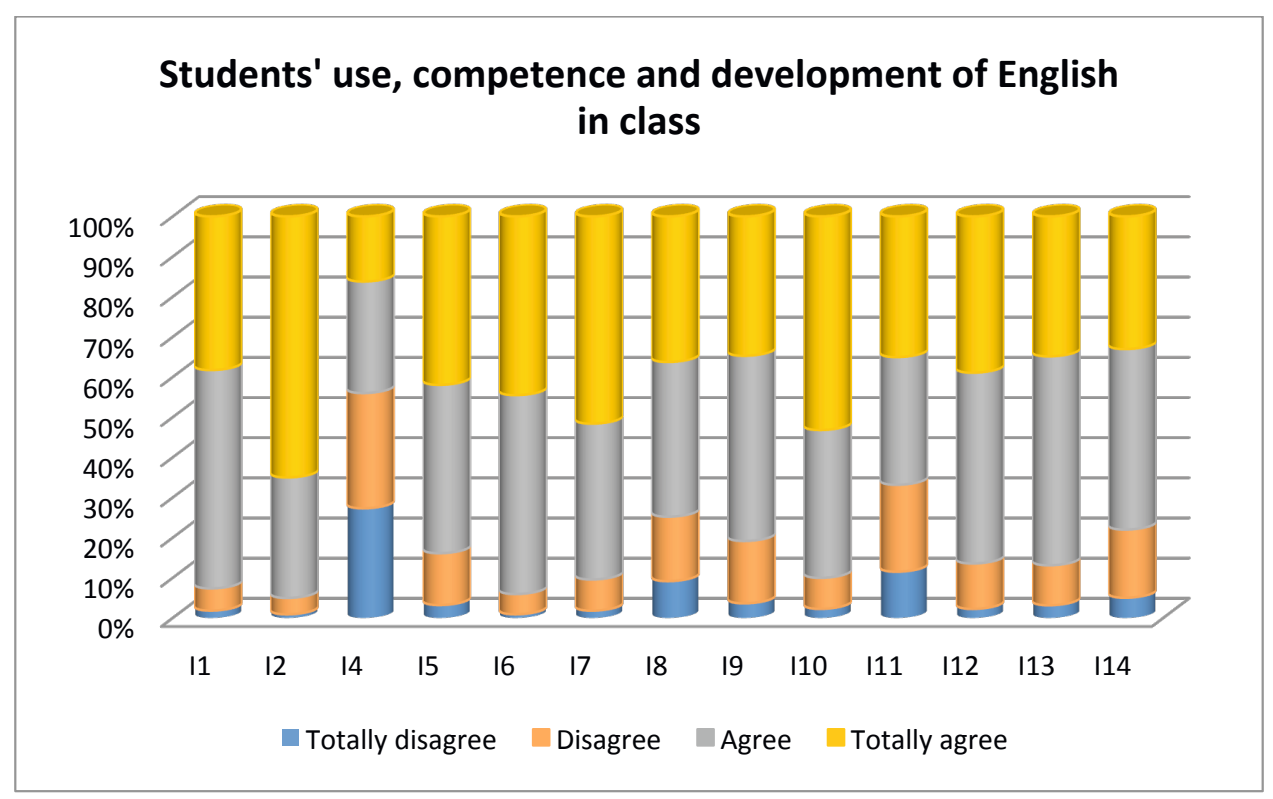

Figure 1. Students' use, competence and development of English in class

If we turn our attention to the first block of survey items, which corresponds to students' use, competence and development of English in class, we can observe that each one of the twelve statements included for evaluation by the informants with regard to their experience of learning and using English in class ${ }^{8}$ has received a high mean value between 3 and 4 in the four-point Likert scale employed to this end, and there appears to be a pleasing amount of harmony in their perceptions of their CLIL experience as a means for FL improvement (see Figure 1). This is a crucial area of interest since foreign language development is naturally a prevailing objective of bilingual programmes in school offered under the CLIL umbrella. In fact, a huge majority of the canvassed subjects report, rather unsurprisingly given the additional target language exposure they have received in class, that they feel their English has improved with the corresponding item that addresses their perception of improvement showing a pleasing mean value of 3.59 .

We must not forget the prevailing objective of improving content subject matter in CLIL programmes, in conjunction with the dual aim of enhancing linguistic proficiency; a highly encouraging majority of subjects agreed that their knowledge of the contents of other subjects delivered in English had improved due to the fact of having participated in a bilingual programme, on scoring a highly consensual mean score of 3.23 in this item.

\footnotetext{
${ }^{8}$ We remind the reader that the precise items from the questionnaire can be consulted in full at the following link: http://revistas.cardenalcisneros.es/index.php/PULSO/article/view/217.
} 
Also, and in consonance with previous similar recent studies in Spanish contexts (e.g. Lasagabaster, 2009; Rubio Mostacero, 2009; Cabezas Cabello, 2010), affective attitudes are also revealed to be positively influenced by participating in a CLIL programme. The majority of the subjects reveal that they have more self-confidence (mean value $=3.2$ ), and an even greater number state that they feel interested in the bilingual class (mean value $=3.41$ ). Similarly, they seem to be happy with the amount of English they use in class, although there seems to be a certain amount of desire for more English in their instructional sessions (mean value $=2.9$ ), which might reflect heightened intrinsic motivation for target language exposure.

It is necessary to highlight in this analysis of the data from the questionnaires that items corresponding both to the key competences for Primary Education and to the to the four blocks of contents for the Compulsory Secondary Education stage regarding foreign languages (Royal Decree 1631/106) have been included in this block to ensure that they have also received an appropriate focus in the CLIL programme (see Figure 2 above). A considerable number of the subjects surveyed claim that these key competences have received adequate attention in their classes (a mean value of 3.39), but we also need to match this assertion with the specific responses corresponding to these four areas. In the first place, our informants have positively evaluated their listening and speaking skills development as adequate with a mean value of 3.29 , and, similarly, the second area of writing and reading shows a mean value of 3.19 , which clearly highlights the students' perceived satisfaction in these first two key competences. The third block of compulsory contents attends to the need for reflection on the target language and the learning process, as well as awareness of the connection between languages, and once again this aspect has been very highly rated, with an average value of 3.38 corresponding to the item which questions respondents as regards their perceived improvement of their understanding of how languages function. In almost exact reflection of this (with a mean value of 3.40), our subjects also claim that their understanding of the connection between English and Spanish has increased, too. The fourth and final block of competences refers to the social and cultural dimension of foreign language learning, and although slightly lower than the previous items, this area has also been positively evaluated, with subjects scoring an average of just over 3 out of 4 in relation to their knowledge of socio-cultural aspects and intercultural awareness. 


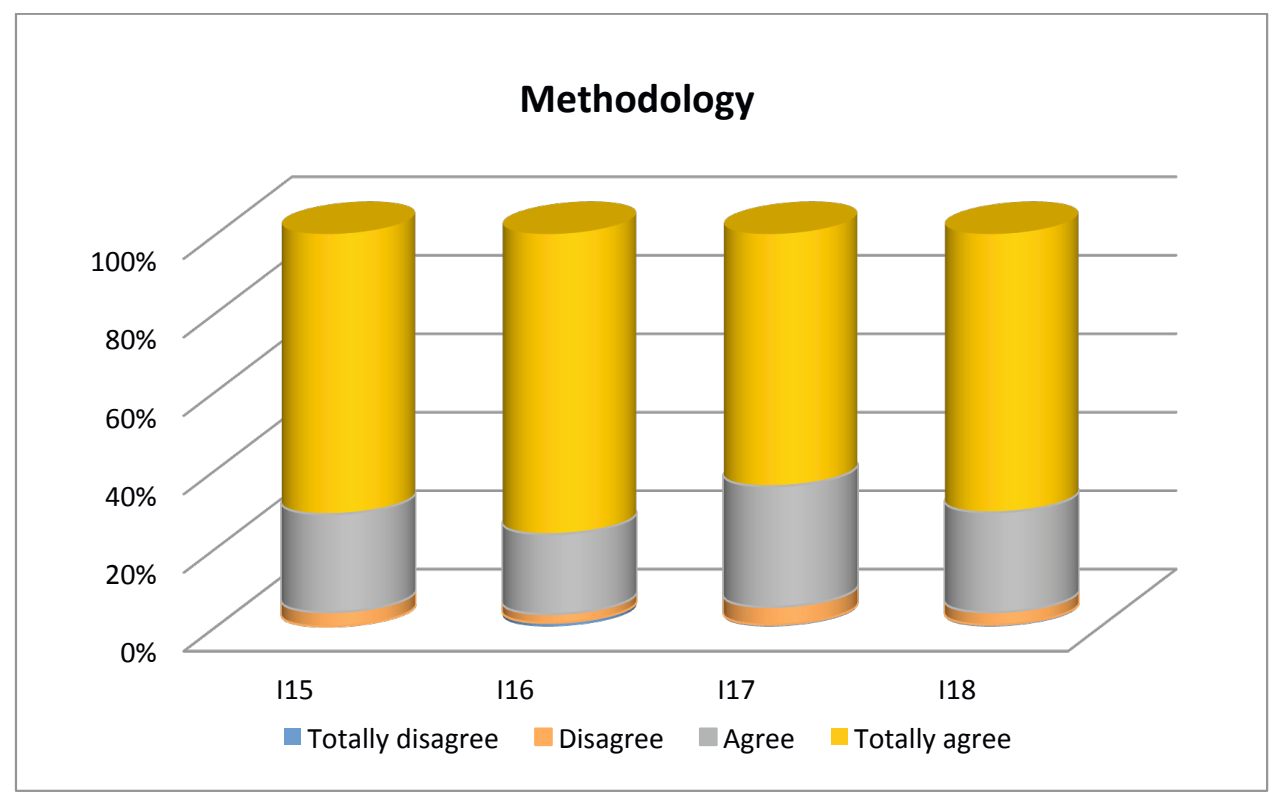

Figure 2. Methodology

We shall now focus on the results obtained for the items corresponding to the second thematic block included in the student questionnaire, that of methodology, which is an aspect that needs attention in research into CLIL programmes, as revealed in earlier qualitative studies carried out by Fernández Fernández et al. (2005), Pena Díaz and Porto Requejo (2008), or Pérez Cañado $(2014,2016 b)$ that have revealed serious deficits in bilingual teaching methodology principally in relation to non-linguistic area teachers and teaching assistants. However, it appears that these shortcomings have not been appreciated in any way whatsoever by our subjects in this study (see Figure 2), as they value their teachers highly and overwhelmingly report the inclusion of tasks and projects in class with mean values of almost the maximum score of 4 (3.68 and 3.72, respectively), as well as a considerable focus on vocabulary learning (mean value $=3.59$ ) and group work $(3.67)$. It seems that, at least from the viewpoint of the students, a highly appropriate task-based and lexically-focused methodology exploiting projects and collaborative learning in groups has filtered into their classes in the bilingual programme, although it might be desirable to explore this area further with a closer comparison of language classes and those other subjects given in English. However, as we shall later discover in the ensuing within-cohort analysis, there are significant differences in each of the four items included in this block according to diverse identification variables. 


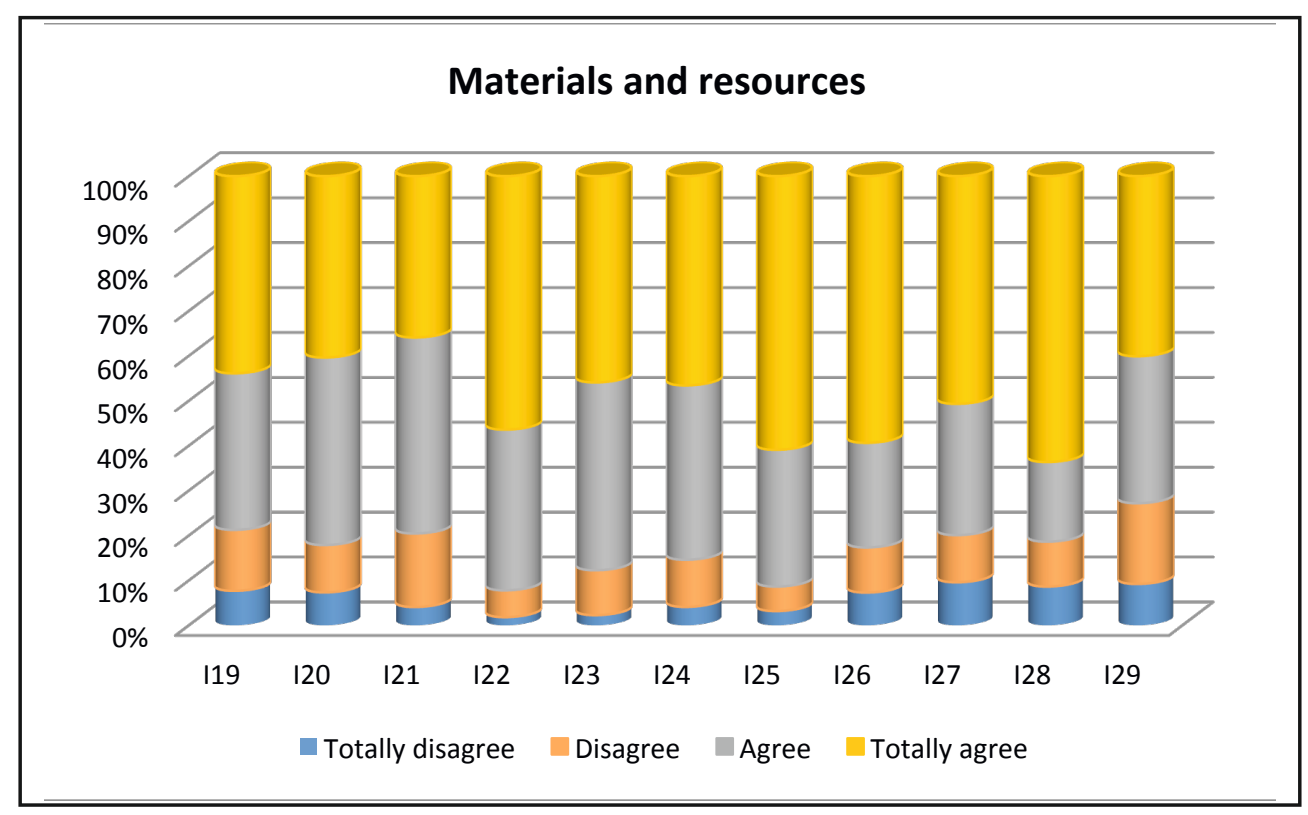

Figure 3. Materials and resources

The data for the third thematic block, materials and resources, should shed light on any perceived deficiencies in this area, especially of interest since researchers such as Cabezas Cabello (2010) have pinpointed the problem of scarce CLIL materials, or poor access to materials in English and ICT, with the lack of CLIL materials being one of the main hurdles teachers currently have to face (Pérez Cañado, 2016b: 6). Yet, as we can see in Figure 3, it seems that our respondents are provided with more than satisfactory access to authentic materials as well adapted authentic materials (3.15 respectively), which they also claim to find interesting and innovative (3.11), as well as suitably adapted to attend to their learning needs, so exposure to appropriate authentic content does not appear to be lacking (3.28) on a global level. They also state that their subject teachers in the bilingual programme encourage them to communicate in English as much as possible (3.31). Along with the materials they use in class, our respondents also seem to value the actions of their teachers, as they report on a high degree of collaboration between the foreign language section and other subject matters. In contrast to earlier analyses addressing the availability of materials (Pérez Cañado, 2014), the lack of ICT tools also appears to be a diminishing problem in our context: multimedia software, online reference material, 2.0 tools such as blogs, wikis, or webquests, and digital whiteboards are invariably rated as frequently used in class, and computer-mediated communication or e-Twinning ${ }^{9}$ the least frequent, but still receiving a mean value over 3 .

\footnotetext{
${ }^{9}$ For further information on this online educational community network, see https://www.etwinning.net/en/ pub/index.htm.
} 


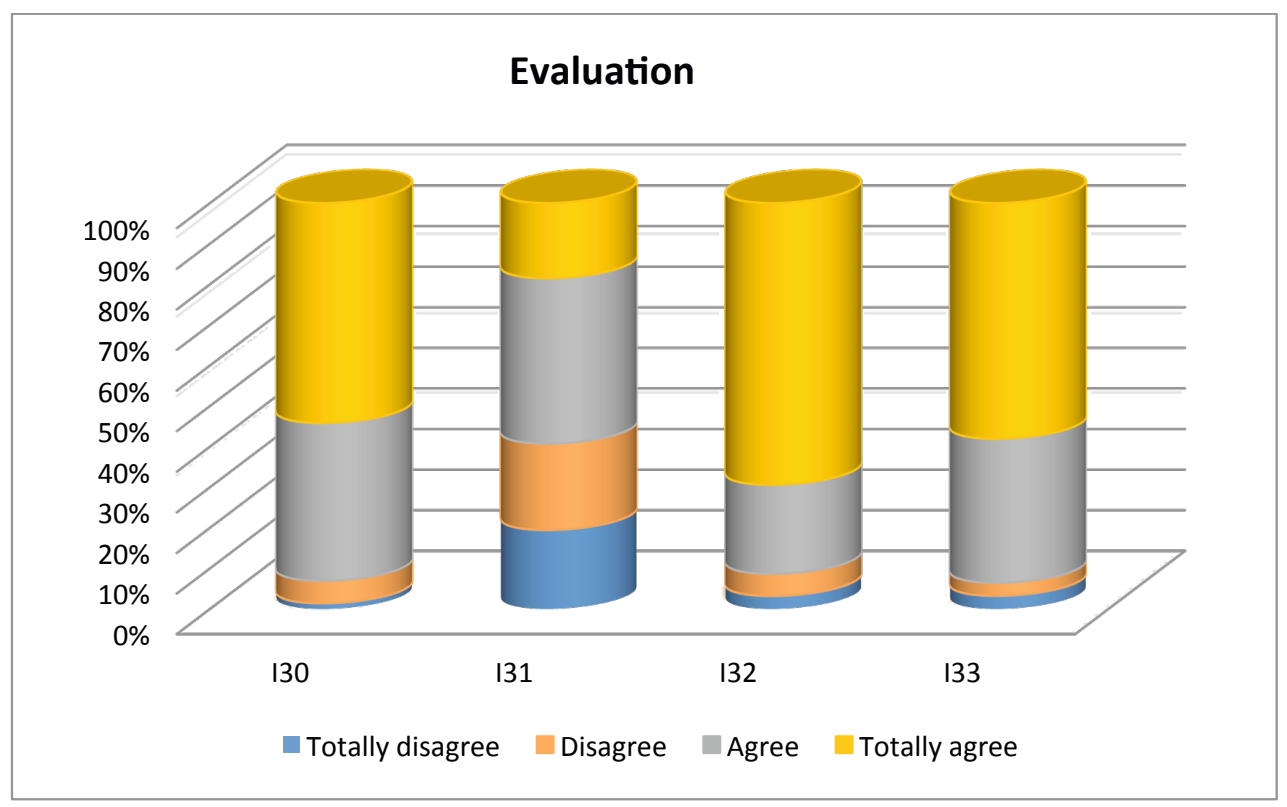

\section{Figure 4. Evaluation}

The fourth thematic block addresses the thorny topic of evaluation, which of course is a fundamental area to explore in any teaching and learning context, and in this case of the currently administered questionnaire exploring students' perceptions of their experience in the bilingual programme, the data culled will hopefully provide an insight into how our subjects are reacting in this relatively new circumstance. Once again, as the chart below clearly illustrates (cf. Figure 4), highly positive reactions were unearthed, with students almost exclusively reporting that all contents covered in their classes were evaluated, along with orals skills, and that both continuous and final assessment procedures were included. Interestingly, lower values than a mean of 3 were received for the item referring to whether content was taken more into account than linguistic expression, which shows that some students still have the enduring view of their language proficiency being of more importance than the contents learned. 


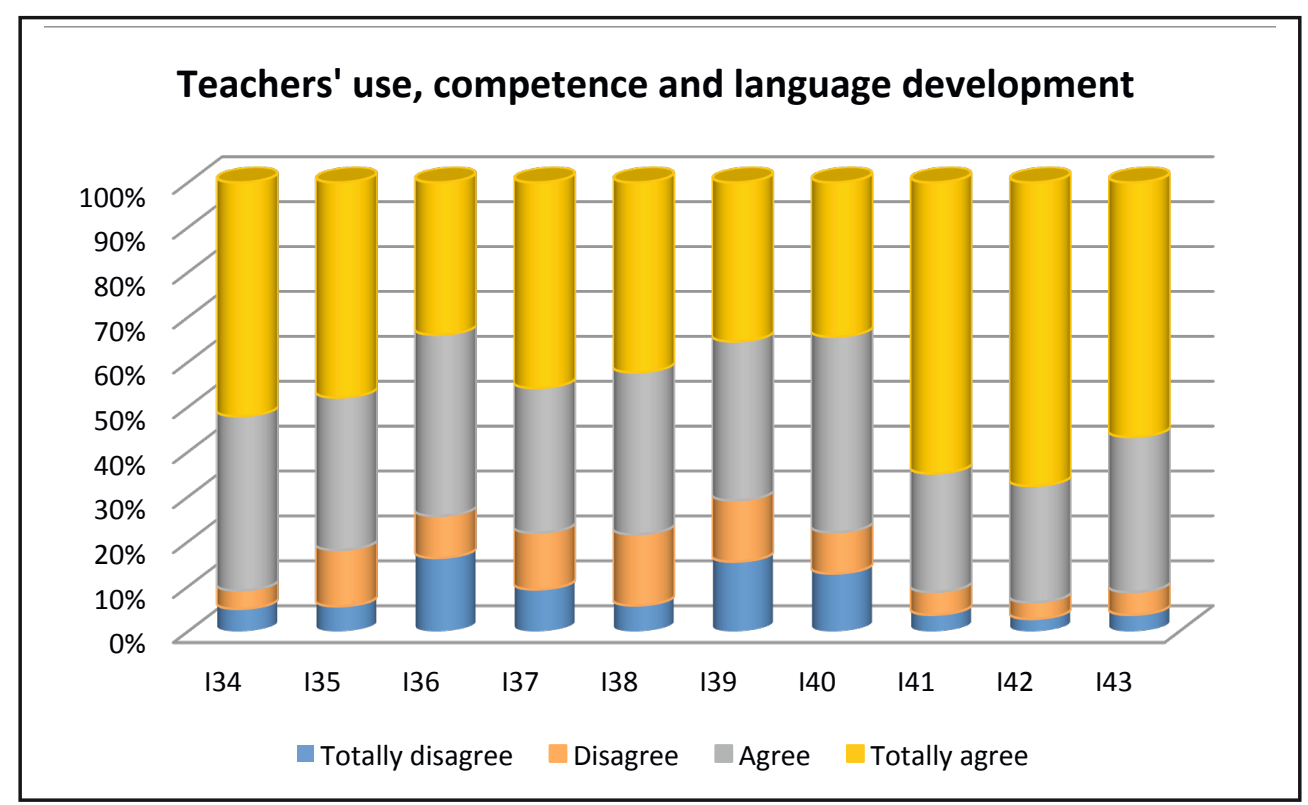

Figure 5. Teachers' use, competence and language development

With regard to the following area of interest pertaining to block 5, teacher training and formation, it appears that similar results have been obtained which corroborate our subjects' positive regard for their teachers. This is particularly encouraging in view of the disappointing results from recent studies which have pinpointed the insecurity felt by many instructors due to their lack of linguistic proficiency in English and with the provision for language improvement opportunities currently viewed as one of the most important lines of action to be undertaken prior to other detected lacunae in the implementation of CLIL programmes (as cited in Pérez Cañado, 2016b: 7). This weakness does not seem to be a worry substantiated by the opinion of the students they teach in the present study, since there seems to be a tremendous defence of the language aptitude of the teachers giving classes at the schools within the bilingual programmes surveyed here. As we can see in Figure 5, the students have rated both their English and their bilingual subject teachers highly as successful practitioners with an adequate capacity of both listening and speaking skills as well as reading and writing, and, slightly less so, as motivators. Interestingly, they have rated their language assistants as less proficient in both aspects, but appreciate their cooperation with teachers. They have also favourably highlighted their teacher's socio-cultural knowledge of English. 


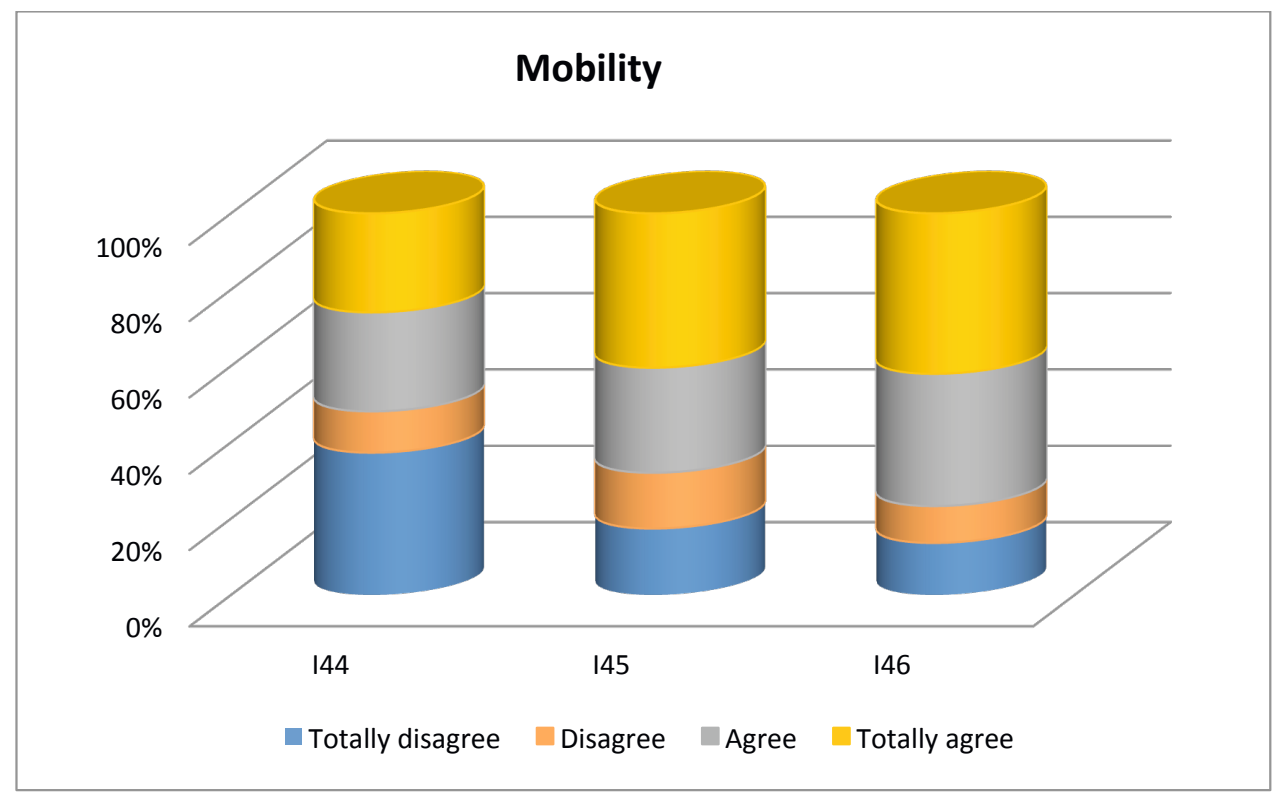

Figure 6. Mobility

The sixth block of content, which elicits information on the levels of participation of students and teachers in exchange programmes, seems to be the aspect which has been least positively scored by our student respondents (see Figure 6), but this could be symptomatic of the lower socio-economic level of the Canarian population in relation to other national and European CLIL centres. This is, however, a matter of concern since student and teacher mobility corresponds to fundamental goals within the objectives of bilingual programmes, and the government provides substantial grants to foster greater movement. This seems to be an area which needs further attention in our context due to the low scoring received by the Canarian students for this block, with the lowest mean value corresponding to student experience of mobility, although it was clear that parental support was high. 


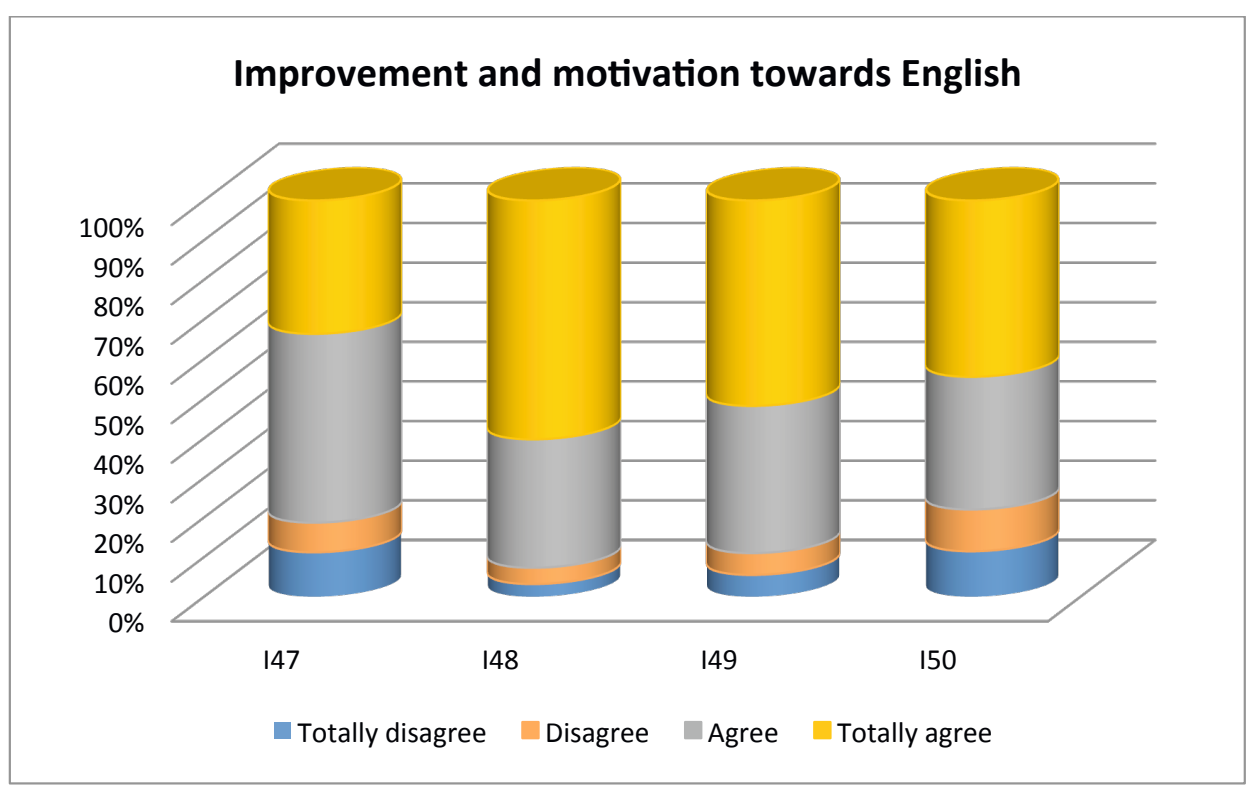

Figure 7. Improvement and motivation towards learning English

The final thematic block to be analysed in the global results for the questionnaire administered to students participating in CLIL programmes in Gran Canaria is that concerning improvement and motivation towards learning English. One of the criticisms that has been voiced, mainly informally, in relation to the provision of bilingual programmes at Primary and Secondary schools, is that of the extra workload that it supposes for the students. According to the responses given in our data (see Figure 7), the majority of the students surveyed agreed that being in the bilingual programme compensates for the increased workload, and this did not seem to raise any cause for concern. Similarly, the experience has been rated highly positively in terms of linguistic improvement in English. As regards motivation, the results obtained from the students' perspective seem to echo the positive effect participating in CLIL programmes has on raising learners' motivational levels that has been reported in other research studies (e.g. Doiz et al., 2014), with most of the subjects claiming that their motivation for learning English had increased as a result of participating in dual-focused learning contexts, as well as their level of English. The only possible area for improvement might be the lack of access to materials outside class, but again this might be more of a geographical or socio-economic quirk of the Canarian location of the study rather than a genuine flaw. 


\subsection{Specific results (within-cohort comparison)}

In order to further enlighten the conclusions that we might reach after examination of the global results for the student questionnaire, and in order to address our second meta-concern, the ANOVA and $t$ test have been employed to determine the existence of statistically significant differences within groups, in terms of the identification variables considered: gender, level, context, years learning English and number of subjects received in English. As a result, we have discovered three principal areas of significant difference which merit further comment in line with the objectives of this article: context and number of years of study, with level also showing considerable notable differences. The variables of gender and number of subjects given in English have displayed much less divergence and, for the purposes of this study, do not need further examination.

In the first place, as regards context, we can see statistically significant differences on 23 items across six of the seven thematic blocks, with the exception of Block 6 (mobility), and these respond to the more positive evaluation of those polled in urban centres. For example, in the case of Block 1, students' use, competence and development of English, as seen in the analysis of the global results when self-evaluating their progress, a large majority of subjects claimed that not only had their English improved, but also their key competences and content knowledge had developed too, whereas a lower quantity of students felt their Spanish had improved. On closer observation of the data, we can see in both the former aspects that the respondents from urban schools scored this aspect more positively. An even greater difference can be seen in their evaluation of their listening and speaking skills, again with those respondents from urban centres providing higher mean values, yet no significant difference can be detected in the case of writing and reading skills. On a metacognitive level, these differences are echoed on examining the responses provided for improvement detected in understanding how languages function and the connection between English and Spanish due to having participated in a bilingual programme at their school. This difference was also affected in affective aspects such as self-confidence, interest and the desire to use more English in class.

As we might expect, in the case of materials and resources (Block 3), students from urban centres showed significant differences in their access to ICT tools in class sessions, which they appear to use with greater frequency than students in rural areas, except in the case of the digital whiteboard (see Figure 7). This might be due to the fact that a greater number of urban centres were polled in the survey, although it is also true that all the Primary centres visited in the course of the investigation were well equipped with digital boards and multimedia equipment, but their use might diminish with Secondary students, as covering other curricular contents in more traditional ways might take over. Although the mean values for the use of 2.0 tools such as wikis or blogs, webquests and online references were all approaching 3 or over, showing widespread use of ICT, these were less common in rural areas. More encouraging was the smaller difference between computer-mediated communication and e-Twinning, with only a minor difference detected. However, a greater area of concern, which echoes previous studies, becomes apparent when we examine the responses which deal with teaching materials, with again significant differences in favour of urban centres of around one point. Students from rural learning contexts report much less exposure to authentic materials, or adapted materials, and show less appreciation of innovative tasks, 
although rural centres note more positively that their teachers collaborate in preparation of materials, thus appreciating the coordination in materials preparation.

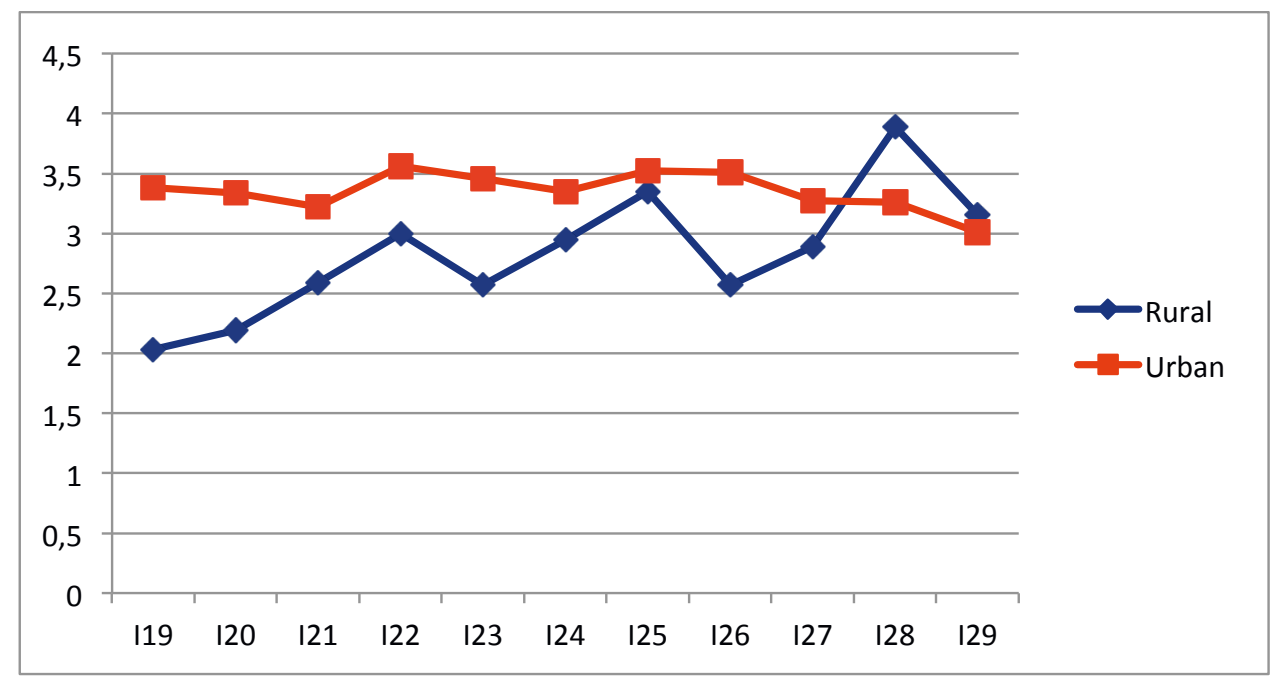

Figure 8. Within-cohort comparison in terms of materials and resources

A further area of interest with differentiation between urban and rural schools seems to be the students' perceptions of their teachers' preparation, with notable significant differences detected in those items eliciting information in relation to both English teachers and those of bilingual contents, again with urban centres scoring higher in terms of receptive and productive skills. There also seems to be a disparity between teachers' knowledge of sociocultural aspects, with a considerable significant difference in favour of urban contexts. A notable exception here is the case of language teaching assistants, who seem to be more highly valued in rural centres.

Finally, as far as motivation is concerned, we need to highlight a further area of significant difference in terms of school setting. The greatest disparity seems to be with regard to the reported increase in motivation, closely followed by perceived improvement in English. It seems that these are factors which are significantly more positively valued in urban centres, which could be due to the fact that students from rural areas seem to report less access to English or exposure to foreign languages outside class than their urban counterparts who live in multicultural urban contexts or tourist areas typical of the Canary Islands. It is, nevertheless, encouraging to see that there is less significant difference in relation to educational context when the increased workload which being in a bilingual programme implies is addressed.

The second area which has produced high incidence of significant difference is that of number of years of study, despite the similarly consistent values between the two groups of analysis consisting of (i) four years or less and (ii) more than four years. Greater differentiation was detected in practically all seven blocks (except mobility) covering aspects 
such as the development of key competences, increased desire for using English in class, frequency of task-based methodology and group work, motivating materials and ICT, and teacher preparation. In fact, the greatest amount of significant difference is to be found in Block 3 (materials and resources) and, and to a greater extent, Block 4 (evaluation), where it is claimed that oral skills are evaluated and continuous evaluation systems are used more frequently by those older respondents who have been learning English for more than four years. There is also some discrepancy with regard to the evaluation of bilingual contents, with this increasing as students make progress over the years. This is in contrast with those findings reported by Lasagabaster and Sierra (2009) described in Section 2 in which the younger learners showed greater motivation.

However, an area worthy of attention here shows up in relation to Block 7 , which addresses improvement and motivation towards learning English. Once again, limited access to materials outside class appears to be more of a concern for younger students, but what stands out here is the significant difference with reference to the increased workload being suitable compensation for being in a bilingual programme, as it seems this is experienced more positively by those who have been learning for fewer years. This significant difference is also borne out when factoring in level, as Secondary students, who may have been learning English for more years, also seem to recognise the effort the increased workload being in a bilingual implies, but with lower mean values. This might indicate the need to sustain and perpetuate motivation as bilingual programmes increase and other factors inherent in different ages and the onset of adolescence appear. If we bear the context of our study in mind, and if we remember that students usually spend an average of 13 years studying English at pre-university level, this may not come as a surprise, and as Madrid (2002) has reported, longitudinal studies on non-CLIL students' motivation indicate that their level of motivation diminishes progressively with time, with students in Primary Education being typically more motivated to learn English than students of the first cycle (the first two years) of Compulsory Secondary Education in the Spanish education system. Cenoz et al. (2013) resort to both psychological and educational factors to explain these results. The former would be based on older students' rejection of the school system as a result of the transition from a family identity to a more individual and peer group identity. The latter is connected with the different teaching methodologies used in Primary and Secondary Education.

With reference to the contrast between the data gathered for Primary and Secondary students, significant differences have also appeared which need further commentary. In the first block, items 1, referring to the development of key competences, and 5, addressing the increase in content knowledge, displayed significant differentiation in favour of Primary students. This means that CLIL programmes need to explore the continuation of curriculum design in order to guarantee the development of key competences and subject matter knowledge in dual-focused content classes, seemingly as far as students' perceptions are concerned. This aspect, of course, would need to be corroborated by proficiency test results, which will constitute a future study with the existing data culled from this large-scale project. The second block focusing on methodology shows a worrying tendency, as it appears that the inclusion of task-based approaches, project work, lexical development and group work diminish from Primary to Secondary levels: it might appear that Primary Education practitioners are more consistent with CLIL methodological recommendations here. The same phenomenon emerges in Block 3 (methodology and resources), when we can observe how Primary students show significant differences in their values relating to the use of adapted authentic materials, ICT 
tools and, in particular, computer-mediated communication or e-Twinning. This would seem to be an area to be attended to in terms of teacher training needs for Secondary teachers, although once again this would need to be corroborated by comparing these items with the teachers' own responses to similar items. The evaluation block also shows significant differences when factoring in level, and once again Primary students view the procedures concerning aspects such as content assessment and continuous evaluation more positively. The only other area to show a significant value here in relation to the Secondary group is that the effort of being in a bilingual group is perceived to be worthwhile.

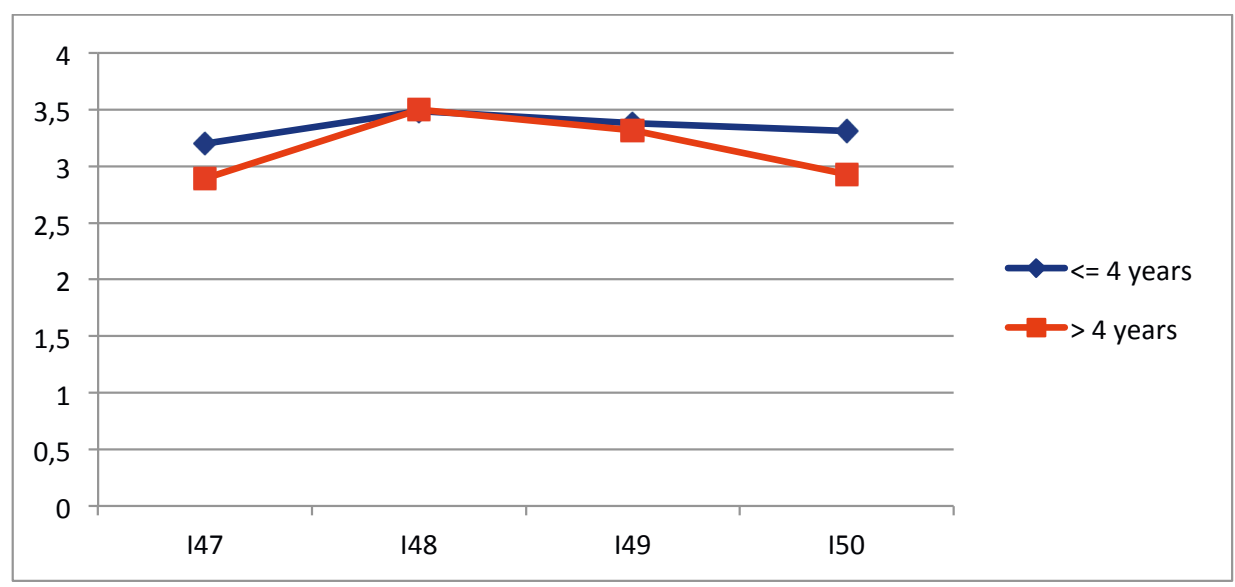

Figure 9. Within-cohort comparison in terms of evaluation

The other socio-demographic variable showing significant differences but to a lesser extent is gender, with females claiming to show greater interest in their bilingual classes, for example, and greater improvement in their English proficiency. As for the variable relating to the number of subjects received in English, it seems that the greater number of subjects has a positive effect on aspects such as perceived key competence development, bilingual content knowledge, awareness of interlanguage connections and both productive and receptive skills development. The greater number of years does not seem to favour learner perceptions of their teachers' linguistic competence, however, as these decrease with the number of subjects received, possibly as a washback effect of greater exposure to more bilingual practitioners (see Figure 9).

\section{Conclusion}

The present study has enabled us to explore the perceptions of learners participating in CLIL programmes in monolingual settings in the Canary Islands vis-à-vis their effectiveness in several key areas, as well as explore the intervention of a selection of variables on 
the almost invariably positive global data that has been elicited across the seven thematic blocks surveyed. An overriding feature we have seen in the results is this cohorts' overall current satisfaction and complacency with both their own burgeoning linguistic development in English, which will need to be correlated with the data culled from the proficiency tests in a subsequent study, and their positive evaluation of their teachers. These informants also appear to exhibit high levels of motivation both with regard to foreign language learning and the content subjects which they receive in English, which undoubtedly reflects previous studies of this nature (e.g. Lasagabaster, 2011).

These revealing and valuable outlooks from one of the key players in bilingual education (i.e. the participating students) have been principally obtained by means of closed-response questionnaires in seven thematic blocks. At first sight, and from a global angle, there appears to be a pleasing amount of harmony in their perceptions of their CLIL experience as a means for FL improvement. Yet, on closer examination, the variables revealed to intervene in our learners' perceptions of their participation in CLIL programmes in the Canary Islands are largely those corresponding to school setting, with urban centres reporting diverging appreciations of aspects such as methodology, materials and resources and access to mobility in comparison with their rural counterparts. These might reflect the findings from earlier studies such as Peña Díaz and Porto Requejo (2008), or Pérez Cañado (2014, 2016b) that revealed shortcomings particularly in relation to the methodology employed by non-linguistic area teachers and teaching assistants, although initially it might appear from the global data that this is not the case.

The other significant variable intervening in our learners' perceptions seems to be that of the number of years previously spent studying English, with older learners showing greater metacognitive awareness of the importance of FL learning, since it could be argued that a CLIL learning experience provides students with growing intercultural competence and the recognition of the importance of a FL for their future academic or professional endeavours. These variables therefore warrant further investigation, and the findings reported here also reveal that greater attention is required for methodological aspects, as well as the use of materials and resources in the preparation of CLIL teachers, which will have implications for future decisions regarding training initiatives in CLIL programmes at both local and national levels. This would seem to suggest that greater training and support is needed for the teachers of content subjects given in English, and that coordination needs to be increased between these teachers and their EFL counterparts. This might imply a wider range of training courses or specialized Master's programmes are required in order for CLIL programmes to continue to expand and improve with greater attention to one of the key stakeholders involved in this educational innovation: the teachers involved in bilingual programmes in the autonomous community targeted in the current study. However, the value of the analysis reported here is that this deficiency has come to the fore by means of an analysis of the perspectives provided by another of the key stakeholders implicated: the students themselves.

\section{REFERENCES}

Cabezas Cabello, J. M. (2010). "A SWOT analysis of the Andalusian Plurilingualism Promotion Plan (APPP)", in M. L. Pérez Cañado (ed.), Proceedings of the 23rd GRETA Convention. Jaén: Joxman, 83-91. 
Cenoz, J., Genesee, F. and Gorter, D. (2013). "Critical analysis of CLIL: Taking stock and looking forward", in Applied Linguistics, 35, 3: 243-262.

Coyle, D. (2013). "Listening to learners: an investigation into 'successful learning' across CLIL contexts", in International Journal of Bilingual Education and Bilingualism, 16, 3: 244-266.

Coyle, D., Hood, P. and Marsh, D. (2010). Content and Language Integrated Learning. Cambridge: Cambridge University Press.

Dalton-Puffer, C., Llinares, A., Lorenzo, F. and Nikula, T. (2014). "You can stand under my umbrella. Immersion, CLIL and Bilingual Education. A response to Cenoz, Genesee \& Gorter (2013)", in Applied Linguistics 35, 2: 213-218.

Doiz, A., Lasagabaster, D. and Sierra, J. M. (2014). "CLIL and motivation: the effect of individual and contextual variables", in The Language Learning Journal, 42, 2: 209-224.

Fernández Fernández, R., Pena Díaz, C., García Gómez, A. and Halbach, A. (2005). "La implantación de proyectos educativos bilingües en la Comunidad de Madrid: las expectativas del profesorado antes de iniciar el proyecto", in Porta Linguarum, 3: 161-173.

Frigols Martín, M. J. and Marsh, D. (2014). Informe de evaluación externa: Programa CLIL de la Consejería De Educación, Universidades y Sostenibilidad de Canarias. Available from http://www.gobiernodecanarias.org/opencmsweb/export/sites/educacion/web/programasredeseducativas/galerias/galeria_documentos/hablar otralengua/Evaluacion_ proceso_implant_CLIL_Canarias.pdf., accessed 19 May, 2017.

Lasagabaster, D. (2011). "English achievement and student motivation in CLIL and EFL settings", in Innovation in Language Learning and Teaching, 5, 1: 3-18.

Lasagabaster, D. and Sierra, J. M. (2009). "Language attitudes in CLIL and traditional EFL classes", in International CLIL Research Journal, 1, 2: 4-17.

Peña Díaz, C. and Porto Requejo, M. D. (2008). "Teacher beliefs in a CLIL education project", in Porta Linguarum, 10, 151-161.

Pérez Cañado, M. L. (2012). "CLIL research in Europe: Past, present, and future", in Internationa Journal of Bilingual Education and Bilingualism 15, 3: 315-341.

Pérez Cañado, M. L. (2014). "Teacher training needs for bilingual education: In-service teacher perceptions, in International Journal of Bilingual Education and Bilingualism, 19, 3: 266-295.

Pérez Cañado, M. L. (2016a). "Evaluating CLIL programmes: Instrument design and validation", in Pulso. Revista de Educación, 39: 72-112.

Pérez Cañado, M. L. (2016b). "Are teachers ready for CLIL? Evidence from a European study", in European Journal of Teacher Education, 39, 2: 202-221.

Pérez-Vidal, C. (2013). "Perspectives and lessons from the challenge of CLIL experiences", in C. Abello Contesse, P. Chandler, M. D. López Jiménez, and R. Chacón Beltrán (eds.), Bilingual and multilingual education in the 21st century. Building on experience. Bristol: Multilingual Matters, 59-82.

Rubio Mostacero, M. D. (2009). Language teacher training for non-language teachers: Meeting the needs of Andalusian teachers for school plurilingualism projects. Design of a targeted training course. Jaén: Universidad de Jaén.

\section{ACKNowledgements}

This work was supported by the Spanish Ministry of Economy and Competitiveness, under Grant FFI2012-32221, and by the Junta de Andalucía, under Grant P12-HUM-23480. We would like to thank the school management, the staff and especially the students who participated in this study. 